Témoigner Témoigner. Entre histoire et mémoire

Getuigen Revue pluridisciplinaire de la Fondation Auschwitz

$122 \mid 2016$

Révisionisme et négationisme

\title{
Patrice Perna et Fabien Bedouel, Kersten, médecin d'Himmler
}

Jean-Pierre Pisetta

\section{Q OpenEdition}

1 Journals

Édition électronique

URL : https://journals.openedition.org/temoigner/4744

DOI : $10.4000 /$ temoigner.4744

ISSN : 2506-6390

Éditeur :

Éditions du Centre d'études et de documentation Mémoire d'Auschwitz, Éditions Kimé

Édition imprimée

Date de publication : 2 mai 2016

Pagination : 181-182

ISSN : 2031-4183

Référence électronique

Jean-Pierre Pisetta, " Patrice Perna et Fabien Bedouel, Kersten, médecin d'Himmler », Témoigner. Entre histoire et mémoire [En ligne], 122 | 2016, mis en ligne le 30 septembre 2021, consulté le 04 janvier 2022. URL : http://journals.openedition.org/temoigner/4744 ; DOI : https://doi.org/10.4000/temoigner. 4744

Ce document a été généré automatiquement le 4 janvier 2022.

Tous droits réservés 


\title{
Patrice Perna et Fabien Bedouel, Kersten, médecin d'Himmler
}

\author{
Jean-Pierre Pisetta
}

\section{RÉFÉRENCE}

Patrice Perna (scénario), Fabien Bedouel (dessin), "Pacte avec le mal”, tome 1, Kersten, médecin d'Himmler, Grenoble, Glénat, 2015, 48 p.

Patrice Perna (scénario), Fabien Bedouel (dessin), “Au nom de l'humanité”, tome 2, Kersten, médecin d'Himmler, Grenoble, Glénat, 2015, 48 p.

1 Le Reichsführer Heinrich Himmler a de terribles douleurs d'estomac qu'aucun médecin allemand n'a pu soulager et, en 1939, avant le début de la guerre, il fait appel à un praticien de nationalité finlandaise appelé Félix Kersten qui, par l'imposition de ses mains et divers massages, accomplit le miracle de le soulager. Ces soins permettent au médecin d'obtenir des faveurs et, d'abord, la libération de personnes impliquées politiquement contre le régime nazi, aussi bien en Allemagne qu'en Hollande où Kersten a une résidence et de nombreux amis.

2 En 1941, le médecin apprend qu'Hitler, agacé par les rapports étroits qu'entretient la couronne néerlandaise avec les milieux juifs, a décidé de déporter massivement le peuple hollandais en Pologne. Aussi incroyable que cela puisse paraître, Kersten aurait obtenu d'Himmler qu'il intervienne auprès d'Hitler pour qu'il renonce à ce projet.

Le récit présenté par le scénariste Patrice Perna et le dessinateur Fabien Bedouel s'articule autour de deux axes : le premier couvre la période de la guerre, le deuxième s'intéresse à la demande de naturalisation suédoise (pourquoi suédoise, l'auteur ne nous le précise pas) introduite par le médecin après la fin des hostilités. Son dossier, qui le décrit pourtant comme un héros, est rejeté par l'administration de Stockholm en raison des rapports qu'a entretenus Kersten avec le régime nazi. Or, les vies qu'il a sauvées étaient au prix de cette proximité. Notamment celles de nombreux prisonniers scandinaves qu'il a pu faire sortir des camps et diriger vers la Suède qui avait accepté 
de les accueillir, et ce par l'intermédiaire de la Croix-Rouge que dirigeait à l'époque le comte Folke Bernadotte (celui-ci, qui avait été assassiné, en Palestine, par des extrémistes en 1948, ne pouvait malheureusement plus témoigner en sa faveur). Par la même occasion, Bernadotte et Kersten avaient obtenu la déviation d'un convoi de plusieurs milliers de Juifs vers la Suisse, déviation autorisée elle aussi par Himmler, toujours en remerciement des soins prodigués par son médecin.

Ces deux albums, dessinés avec une sobriété raffinée et percutante, portent à la connaissance du grand public des événements étonnants et posent à ce dernier une question cruciale : quand on a pactisé « avec le mal » ou " avec le diable » (les premiers termes sont sur la couverture, les seconds, étrangement, sur la page intérieure de titre !), peut-on réellement bénéficier de circonstances atténuantes si l'on a malgré tout sauvé des vies, car, soigner un tel individu, c'était aussi lui permettre de mener à bien ses fonctions de bras droit d'Hitler et, partant, son œuvre dévastatrice? Question épineuse, à laquelle les albums ne répondent qu'en rapportant des faits, c'est-à-dire sans trancher, laissant ainsi le lecteur se faire lui-même, et bien malaisément d'ailleurs, une opinion.

Cependant, était-il bien nécessaire, dans cette production mesurée et juste, de consacrer une page entière aux secrets d'alcôve d'un sous-fifre nazi et aux rondeurs de son amante, qui, la pauvre, en plus d'être offerte à nos regards dans son plus simple appareil, reçoit une correction pour avoir osé faire le salut nazi à son amant déjà rhabillé, lui ? La femme, de préférence nue, a décidément bon dos. 